\title{
MANAJEMEN DISTRIBUSI KOMODITAS HARGA BAHAN PANGAN DI INDONESIA DENGAN METODE LEAST COST
}

\author{
Nafila Salsabila, Shafa Andrian Putri, Tasya Fitri Azzahra, Amelia Maharani \\ Prodi Manajemen, Universitas Pembangunan Jaya
}

\begin{abstract}
Abstrak
Penyelenggaraan Makanan Institusi/massal (SPMI/M) adalah penyelenggaraan makanan yang dilakukan dalam jumlah besar atau massal. Batasan mengenai jumlah yang diselenggarakan di setiap negara bermacam-macam, sesuai dengan kesepakatan masing - masing serta akan melalui proses panjang dalam penyelenggaraan pori makanan tersebut. Permasalahan transportasi yang berhubungan dengan distribusi barang dan jasa dari berbagai sentra produksi ke beberapa lokasi penjualan. Pendistribusian memegang peran penting karena tanpa adanya pola distribusi yang tepat, maka proses pendistribusiannya dapat memakan biaya yang tinggi dan waktu yang relatif lama. Salah satu solusi program linear dalam pendistribusian barang adalah dengan menggunakan metode transportasi, supaya pendistribusian barang berjalan seefektif mungkin dengan pengalokasian biaya yang minimum. Metode Least Cost merupakan salah satu teknik solusi dalam transportasi. Metode ini didasarkan pada aturan atau pengalokasian normatif dari persediaan dan kebutuhan sumber dalam suatu matriks transportasi tanpa perhitungan besar-besaran ekonomis. Kata kunci: Manajemen Pendistribusi Least Cost, Komoditas Harga, Bahan Pangan ,
\end{abstract}

\section{PENDAHULUAN}

Manajemen pengetahuan merupakan rangkaian dalam proses untuk membuat, menyimpan, mentransfer, dan menerapkan pengetahuan dalam organisasi. Sistem manajemen pengetahuan keseluruhan adalah upaya diseluruh untuk mengumpulkan, menyimpan, mendistribusikan, dan menerapkan data digital dan pengetahuan. Pengetahuan adalah konsep, pengalaman, dan pendekatan yang memberikan kerangka dasar untuk menciptakan, mengevaluasi dan menggunakan informasi. Untuk mengubah informasi menjadi pengetahuan harus memanfaatkan lebih banyak lagi sumber daya untuk menemukan pola, aturan, dan konteks dimana pengetahuan tersebut berguna. Manajemen pengetahuan adalah sekumpulan proses ynag dikembanghkan dalam organisasi untuk menciptakan, mengumpulkan, menyimpan, memelihara, dan menyebarkan pengetahuan yang dimiliki.Sistem manajemen pengetahuan adalah system yang mendukung penciptaan, 
pengambilan, penyimpanan, dan penyebaran keahlian dan pengetahuan yang dimiliki. Manajemen pengetahuan telah menjadi aspek penting di banyak di mana para manajernya menyadari bahwa keberhasilan mereka bergantung pada kemampuan untuk menciptakan dan mengelola pengetahuan.

Manajemen rantai pasokan komoditi pertanian berbeda dengan manajemen rantai pasokan komoditi non- pertanian, karena berkaitan dengan sifat dari produk pertanian yang mudah rusak, kemudian proses penanaman, pertumbuhan dan pemanenan tergantung pada iklim dan musim, serta hasil panen memiliki bentuk dan ukuran yang bervariasi. Seluruh faktor tersebut harus dipertimbangkan dalam desain manajemen rantai pasok komoditi pertanian guna mendapatkan sistem rantai pasok yang komprehensif, efektif, efisien, responsif dan berkelanjutan.

Dalam persaingan saat ini, para pelaku usaha dituntut untuk menyadari bahwa persaingan yang terjadi merupakan persaingan antar jaringan rantai pasokan. Para pelaku usaha dalam suatu rantai pasokan harus mampu menyampaikan produk yang sesuai dengan keinginan konsumen dari segi kualitas, kuantitas, harga, waktu dan tempat yang tepat, mengingat bahwa pesaing dalam abribisnis ini juga termasuk yang berasal dari luar negeri yang dalam beberapa hal telah menerapkan manajemen dan teknologi pertanian yang lebih maju, antara lain ditandai dengan masih dominannya buah impor di pasar dalam negeri kita. Dengan karakteristik produk pertanian tersebut maka harus disusun suatu manajemen rantai pasok yang tepat.

Penyelenggaraan makanan institusi adalah serangkaian kegiatan mulai dari perencanaan menu, penyediaan atau pembelian bahan makanan, penerimaan, penyimpanan dan penyaluran bahan makanan, persiapan dan pemasakan bahan makanan, pencatatan dan pelaporan serta evaluasi yang dilaksanakan dalam rangka penyediaan makanan bagi kelompok masyarakat di sebuah institusi. Selain untuk memenuhi kebutuhan gizi, penyelenggaraan makanan bertujuan untuk menyediakan makanan yang baik dari segi mutu, jenis maupun jumlahnya.

Penyelenggaraan makanan adalah rangkaian kegiatan mulai dari perencanaan menu sampai dengan pendistribusian makanan kepada konsumen dalam rangka pencapaian status kesehatan yang optimal melalui pemberian makanan yang tepat dan termasuk kegiatan pencatatan, pelaporan, dan evaluasi (Depkes 2013). Penyelenggaraan makanan di 
bertujuan untuk menyediakan makanan yang berkualitas dan layak. Makanan harus memenuhi kebutuhan gizi, selera atau cita rasa dan untuk mempertahankan status gizi yang optimal untuk mempercepat proses penyembuhan (Yunita, 2014).

Distribusi merupakan suatu proses pengiriman barang dari suatu sumber ke konsumen. Dalam proses pendistribusian, salah satu hal yang harus diperhatikan adalah kepuasan konsumen karena akan berpengaruh terhadap keberhasilan penjualan produk. Salah satu kepuasan konsumen adalah barang dapat sampai ke konsumen dengan tepat waktu dan produk sesuai dengan keinginan atau kebutuhannya. Keberhasilan distribusi dapat meningkatkan kenaikan angka penjualan yang dapat dilihat dari banyaknya penjualan. Untuk mencapai keberhasilan distribusi dan penjualan, permasalahan distribusi ini menjadi sangat penting karena berhubungan dengan biaya transportasi yang berpengaruh terhadap total biaya produksi.

Permasalahan distribusi barang merupakan aspek yang harus diperhatikan karena permasalahan tersebut memiliki pengaruh yang cukup besar terhadap biaya dan tingkat pelayanan kepada konsumen. Ada beberapa kendala yang harus dihadapi dalam proses pendistibusian, seperti jumlah permintaan barang yang berbeda-beda pada setiap konsumen, kapasitas kendaraan, batas waktu pengiriman, kecepatan rata-rata yang dapat ditempuh pada jalur dan waktu tertentu dan lokasi konsumen yang berbeda-beda. Oleh karena itu diperlukan suatu cara agar proses distribusi dapat berjalan dengan lancar dan tepat waktu dengan biaya produksi yang minimum.

Metode transportasi digunakan untuk mengatur distribusi dari sumber yang menyediakan produk yang sama ke tempat-tempat yang membutuhkan. Ada beberapa metode untuk mencari solusi layak dasar awal yaitu North West Corner, Least Cost, dan Aproksimasi Vogel. Sedangkan metode untuk mengecek optimal ada dua yaitu Stepping Stone dan MODI (Modifield Distribution). Alokasi produk ini harus diatur sedemikian rupa, karena terdapat perbedaan biaya-biaya dari satu sumber ke suatu tempat tujuan yang berbeda-beda.

Metode transportasi ini digunakan disaat seseorang menentukan cara pengiriman (distribusi) suatu jenis barang dari beberapa sumber (lokasi penawaran) ke beberapa tujuan (lokasi permintaan) yang dapat meminimumkan biaya. Sasaran dalam persoalan transportasi ini adalah mengalokasikan barang yang ada pada sumber sedemikian rupa 
hingga terpenuhi semua kebutuhan pada lokasi permintaan. Adapun tujuan penggunaan metode transportasi sebagai upaya untuk pendistibusian barang adalah agar supply (persediaan) dari beberapa sumber dapat dilakukan secara efektif dengan biaya yang minimum ke beberapa lokasi permintaan.

\section{METODE PENELITIAN}

Jenis penelitian ini merupakan penelitian Supply chain mangement yang merupakan model manajemen strategi berdasarkan teknologi informasi modern, melalui hubungan kerjasama strategi dan pembagian informasi antara yang berpartisipasi akan dibangun, proses produk raw material supply,distribution, processing akan di integrasikan. Sedangkan untuk logistik dan arus modal di seluruh rantai pasok akan diatur dan dikontrol. Sehingga tujuan mengurangi resiko operasi, meningkatkan daya saing dan mendapatkan keuntungan untuk yang berpartisipasi akan tercapai. Tujuan utama dari Supply chain management adalah untuk menangani ketidapastian yang diakibatkan oleh fluktuasi permintaan, meningkatkan respon pasar dan memenuhi permintaan pelanggan. Menurut Ellram (1991) dan Wisner (2003) Supply chain management dapat didefinisikan sebagai “desain dan manajemen dari kesempurnaan, nilai tambah dari suatu proses melewati batas - batas terkait demi tercapainya kebutuhan real customer.

Pengembangan dan integrasi sumber daya manusia serta teknologi sangat menentukan kesuksesan integrasi rantai pasok. SCM diintegrasikan dengan pendekatan untuk perencanaan dan pengawasan arus material dari supplier melewati jaringan distribusi hingga sampai ke tangan custome Secara umum konsep Supply Chain Management (SCM) menurut Martin Christopher dari Cranfield University adalah proses strategis yang mengatur tentang pengadaan, perpindahan dan penyimpanan dari material, part atau barang jadi serta aliran informasi yang berhubungan dari organisasi.

Metode transportasi berhubungan dengan distribusi suatu produk tunggal dari beberapa sumber dengan penawaran terbatas, menuju beberapa tujuan, dengan permintaan tertentu, pada biaya distribusi minimum. Karena hanya ada satu macam barang, suatu tempat tujuan dapat memenuhi permintaan-nya dari satu atau lebih sumber. Untuk mendapat biaya yang minimum, maka alokasi produk harus diatur sedemikian rupa, karena terdapat perbe-daan biaya-biaya alokasi, baik dari sumber ke tujuan atau sebaliknya. 
Masalah transportasi dapat ditempatkan dalam suatu tabel khusus yang dinamakan tabel transportasi. Sumber ditulis dalam baris-baris dan tujuan dalam kolom-kolom. Dalam tabel transportasi terdapat $\mathrm{m} \times \mathrm{n}$ ko-tak. Biaya transportasi per unit barang $\mathrm{C}_{\mathrm{ij}}$ dicatat pada kotak kecil di bagian kanan atas setiap kotak. Permintaan dari setiap tujuan terdapat pada baris paling bawah, sementara penawaran setiap sumber dicatat pada kolom paling kanan. Kotak pojok kiri bawah menunjukkan kenyataan bahwa penawaran atau supply (S) sama dengan permintaan atau demand (D). Variabel $\mathrm{X}_{\mathrm{ij}}$ pada setiap kotak menunjukkan jumlah barang yang diangkut dari sumber i ke tujuan j. Bentuk umum dari tabel transportasi dapat dilihat pada Tabel

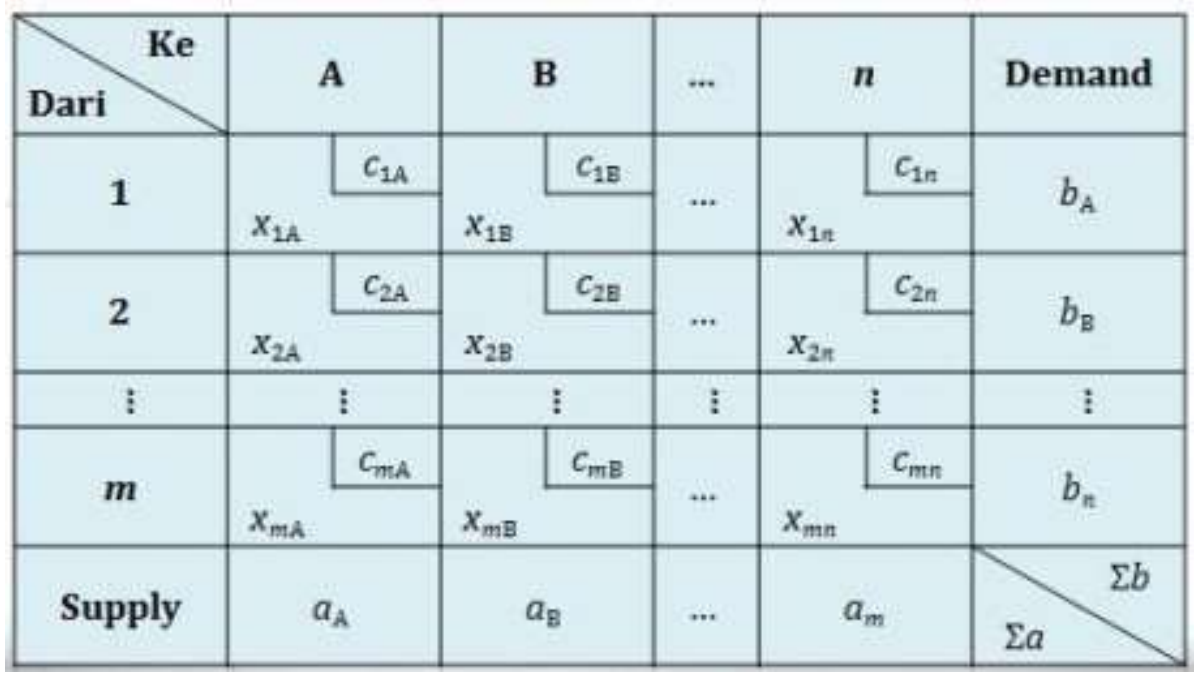

Sumber : Materi Pembelajaran Management Science

Metode Least-Cost melakukan alokasi secara sistematik pada kotak-kotak berdasarkan biaya transport minimum. Langkah-langkah metode ini adalah :

1. Pilih kotak dengan biaya transpor $\left(\mathrm{C}_{\mathrm{ij}}\right)$ terkecil kemudian alokasikan penawaran atau permintaan sebanyak mungkin. Untuk $C_{i j}$ terkecil, $X_{i j}=$ minimum $\left[S_{i}, D_{j}\right]$ yang akan menghabiskan baris i atau kolom $\mathrm{j}$. Baris $\mathrm{i}$ atau kolom $\mathrm{j}$ yang telah dihabiskan akan dihilangkan.

2. Dari sisa kotak yang ada (kotak yang tidak dihilangkan), pilih lagi Cij terkecil dan alokasikan sebanyak mungkin pada baris i atau kolom j.

3. Proses ini akan terus berlanjut sampai semua penawaran dan permintaan terpenuhi.

\section{HASIL DAN PEMBAHASAN}


Sebagaimana telah disampaikan pada bagian pendahuluan sebelumnya, secara umum rantai pasokan berkaitan dengan aliran dan transformasi barang dan jasa mulai dari tahapan penyediaan bahan baku hingga produk akhir sampai di tangan konsumen. Lebih jelasnya, definisi rantai pasokan (supply chain) adalah: "A supply chain encompasses all activities associated with the flow and transformation of goods and services from the raw material stage to the end user (customer), as well as the associated information flows. The suuply chain also integrated group of process to source, make, and deliver product." (Russel and Taylor, 2009: 406) Rantai pasokan merupakan segala aktivitas yang terintegrasi termasuk didalamnya juga aliran informasi yang berkaitan dengan tiga aspek, yaitu:

(1) sumber;

(2) proses produksi, dan

(3) proses penghantaran produk. Terdapat tiga komponen dalam rantai pasokan, yaitu :

1) Rantai pasokan hulu (upstream supply chain), meliputi berbagai aktivitas dengan para penyalur, antara lain berupa pengadaan bahan baku dan bahan pendamping.

2) Rantai pasokan internal (internal supply chain), meliputi semua proses pemasukan barang ke gudang yang digunakan sampai pada proses produksi. Aktivitas utamanya antara lain produksi dan pengendalian persediaan.

3) Rantai pasokan hilir (downstream supply chain), meliputi semua aktivitas yang melibatkan pengiriman produk kepada pelanggan. Fokus utama kegiatannya adalah distribusi, pergudangan, transportasi dan pelayanan serta perencanaan Menu Makanan.

Kebutuhan Bahan Makanan. Kebutuhan bahan makanan adalah kegiatan penyusunan kebutuhan bahan makanan yang diperlukan untuk pengadaan bahan makanan agar tercapainya usulan anggaran dan kebutuhan bahan makanan untuk dalam satu tahun anggaran. Seluruh kebutuhan bahan makanan di langsung ditangani instalasi gizi, pembelian bahan makanan per hari untuk makanan basah yang disesuaikan dengan kebutuhan dan untuk makanan kering persediaan yang dibutuhkan untuk kebutuhan.

Pemesanan dan pembelian bahan makanan merupakan penyusunan permintaan bahan makanan berdasarkan menu atau pedoman menu dan rata-rata jumlah pasien. Dalam pemesanan dan pembelian bahan makanan tidak ada sistem yang dibuat, pemesanan bahan manakan hanya dilakukan oleh ka. instalasi gizi, kebutuhan bahan makanan. 
Penerimaan bahan makanan adalah suatu kegiatan yang meliputi pemeriksaan atau penelitian, pencatatan, dan pelaporan tentang macam, kualitas, dan kuantitas bahan makanan yang diterima sesuai dengan pesanan serta spesifikasi yang telah ditetapkan. Proses penerimaan bahan makanan secara sistematis tidak dilakukan karena mulai dari proses pemesanan, pemeriksaan, dan pembelian dilakukan oleh instalasi gizi termasuk memeriksa jika ada kekurangan.

Metode Lowest Supply Lowest Cost merupakan salah satu metode transportasi yang digunakan untuk menentukan solusi fisibel awal. Berdasarkan penelitian Kantharaj (2018) dengan judul " A New Approach to Find The Initial Basic Feasible Solution of Cost Minimization Transportation Problem" bahwa sebuah perbandingan metode Lowest Supply Lowest Cost dengan metode lain menunjukkan metode Lowest Supply Lowest Cost memberikan hasil yang lebih baik. Sehingga dengan menggunakan metode Lowest Supply Lowest Cost memberikan solusi yang lebih optimal dengan mengestimasi biaya dimasing-masing alokasi tujuan.

\section{KESIMPULAN}

. Manajemen rantai pasokan bahan pangan di satu sisi masih termasuk kategori tradisional, dimana mayoritas petani (kecil, menengah) langsung menjual kepada pedagang pengumpul tanpa melakukan sortasi dan grading, atau yang dikenal dengan sistem abres. Proses sortasi dan grading dilakukan oleh antara lain pedagang pengumpul, supplier. Sementara itu di sisi lainnya, manajemen rantai pasokan buah juga telah memiliki pola kemitraan (partnership), dimana telah ada kontrak kerjasama, biasanya terjadi pada tingkat supplier (middle man) dengan supermarket, restauran, hotel, juga dengan pedagang besar di tujuan- tujuan pasar. Distribusi berkaitan erat dengan kegiatan transportasi yang memadai. Permasalahan distribusi barang merupakan aspek yang harus diperhatikan karena permasalahan tersebut memiliki pengaruh yang cukup besar terhadap biaya dan tingkat pelayanan kepada konsumen. Maka diperlukan cara untuk mengatasi suatu pendistribusian barang dengan menggunakan metode transportasi, sehingga meminimalisasi biaya distribusi total. Metode Least Cost dapat dijadikan sebagai salah satu solusi teknik solusi dalam transportasi sehingga pendistribusian barang dapat dilakukan seefektif mungkin dengan biaya yang minimum.

\section{DAFTAR PUSTAKA}


Anggraini, D., Hamiza, A., Doktoralina, C. M., \& Anah, S. (2018). Application of Supply Chain Management Practices in Banks: Evidence from Indonesia. International Journal of Supply Chain Management, 7(5), 418-427.

Khantaraj, Shankar. (2018). A New Approach to Find the Initial Basic Feasible Solution of Cost Minimization Transportation Problem. International Journal of Management and Applied Science, 4, 1-2.

Damayanti, K., Fardinal., (2019). The Effect of Information Technology Utilization, Management Support, Internal Control, and User Competence on Accounting Information System Quality. Schollars Bulletin, 5(12), 751-758.

Putra, Y. M. (2019). Sistem Manajemen Pengetahuan. Modul Kuliah Sistem Informasi Manajemen. FEB-Universitas Mercu Buana: Jakarta

Sari, Purnama Diah, Faigiduhu Bu'ulolo, dan Suwarno Ariswoyo. (2013). Optimasi Masalah Transportasi dengan Menggunakan Metode Potensial pada Sistem Distribusi PT. XYZ. Jurnal Saintia Matematika 1(5), 407 - 418.

Simbolon, Ld, Situmorang. M,dan Napitupulu. N. (2014). Aplikasi Metode Transportasi dalam Optimasi Biaya Distribusi Beras Miskin (Raskin) pada Perum Bulog Sub Divre Medan. Jurnal Saintia Matematika, 2(3), 299-311.

Paoce Pratama, Hendy Tannady, Filscha Nurprihatin, Heksa Bekti Ariyono, Setyo Melany Sari. Identifikasi Resiko Ergonomi Dengan Metode Quick Exposure Check dan Nordic Body Map . Jurnal Pasti, 11(01):13-21, 2017.

Filscha Nurprihatin, Hendy Tannady, Mirna Lusiani, Gidion Karo-Karo, Renatha. Algoritma KMeans Clustering Untuk Menentukan Lokasi Pusat Distribusi Ritel Dengan Mempertimbangkan Jumlah Permintaan . Jurnal Pasti, 11(01):32-44, 2017.

Christian Lois, Janny Rowena, Hendy Tannady. Perencanaan dan Pengendalian Persediaan Bahan Baku Benang Dengan Lot Sizing Economic Order Quantity (Studi Kasus:CV. Prima Sejati, Tangerang, Banten). Journal of Industrial Engineering and Management System (JIEMS), 10(02):111-118, 2017.

Bagaskara Pratama, Hendy Tannady, Panca Jodiawan. Analisa Pengaruh Kualitas Pelayanan Terhadap Kepuasan Pelanggan (Studi Kasus di NN Laundry, Jakarta Selatan). Jurnal Teknik dan Ilmu Komputer (JTIK), 06(24):435-442, 2017. 
Helena Sisilia Ratna Soetopo, Hendy Tannady. Process Capability Analysis Pada Nut (Studi Kasus:PT. Sankei Dharma Indonesia). Jurnal Teknik Industri (JATI), 12(02):137-142, 2017. Hendy Tannady, Kenrick Filbert. Pengendalian Persediaan Dengan Menggunakan Metode Economic Order Quantity Dan Silver Meal Algorithm (Studi Kasus:PT. SAI). Jurnal Teknik dan Ilmu Komputer (JTIK), 07(25):37-43, 2018.

Hendy Tannady. Mengkaji Kepuasan Pelanggan Terhadap Kualitas Layanan E-Commerce Dengan Menggunakan Metode Importance Performance Analysis 3 Dimensi. Journal of Business \& Applied Management, 11(01):116-135, 2018.

Hendy Tannady, Ruth Elisa Rumawan, Fuji Rahayu Wilujeng, Glisina Dwinoor Rembulan. Analisis Produktivitas Operator Kasir Menggunakan Metode Work Sampling: Studi Kasus Gerai Chatime Mangga Besar. Jurnal Teknologi, 9(2):10-15, 2019.

Yuliana, Hendy Tannady. Faktor Determinan Performa Pekerja Konstruksi Melalui Media Motivasi. Journal of Business and Applied Management, 12(2):169-185, 2019.

Hendy Tannady, Yohanes Dwi Pratama. Analisis Perencanaan Persediaan Bahan Baku Menggunakan Metode Economic Order Quantity Dengan Pertimbangan Stockout Cost (Studi Kasus PT. Multi Logam Presisi). Jurnal Spektrum Industri, 17(2):93-97, 2019.

Hendy Tannady, Dwi Yanasari, Salma Nur Kamila, Vinna Adhe Fitria, Ramdhan Sofyan. Upaya Meningkatkan Kualitas Pelayanan Di Outlet Hennes \& Mauritz Widforss Menggunakan Analisis Service Quality. Journal of Business and Applied Management, 13(1):19-32, 2020. Hendy Tannady, Yohanes Totok Suyoto, Fuji Rahayu Wilujeng. Usulan Perbaikan Tata Letak Mesin Pada Pabrik Segel Plastik (Studi Kasus PT. Sinwa Perdana Mandiri). Journal of Industrial and Manufacture Engineering, 4(1):22-27, 2020.

Hendy Tannady. Analisis Perbaikan Terhadap Antrian Pada Pom Bensin Rawalumbu. Jurnal Ilmiah Teknik Industri, 8(2):148-152, 2020.

Hendy Tannady, Tigor Sitorus. (2017). Role of Compensation, Organization Culture, and Leadership on Working Motivation of Faculty Member (Study Case:Universities in North Jakarta). International Organization of Scientific Research-Journal of Business and Management (IOSR-JBM), 19(10) Ver.3, 41-47, 2017.

Hendy Tannady, Ismuhadjar, Alex Zami. (2017). Factors Affecting The Performance of Driver : The Experience of Transjakarta Bus Driver. International Journal of Research Science \& Management, 04(11), 22-28. 
Hendy Tannady, Yona Maimury. (2017). Increasing the Efficiency and Productivity in the Production of Low Voltage Switchboard Using Resource Constrained Project Scheduling. Journal of Industrial Engineering and Management (JIEM), 11(01), 01-33.

Mieke Rahayu, Fahmi Rasid, Hendy Tannady. (2018). Effects of Self Efficacy, Job Satisfaction, and Work Culture Toward Performance of Telemarketing Staff in Banking Sector. South East Asia Journal of Contemporary Business, Economics and Law, 16(5), 47-52.

Hendy Tannady, Filscha Nurprihatin, Hendy Hartono. (2018). Service Quality Analysis of Two of The Largest Retail Chains With Minimart Concept in Indonesia. Business : Theory and Practice, 19, 177-185.

Mieke Rahayu, Fahmi Rasid, Hendy Tannady. (2019). The Effect of Career Training and Development on Job Satisfaction and its Implications for the Organizational Commitment of Regional Secretariat (SETDA) Employees of Jambi Provincial Government. International Review of Management and Marketing, 9(1), 79-89.

Hendy Tannady, Henny Tannady, Ismuhadjar, Alex Zami. (2019). The Effect of Organizational Culture and Employee Engagement on Job Performance of Healthcare Industry in Province of Jakarta, Indonesia. Quality : Access to Success, 20(169), 18-22.

Hendy Tannady, Fergyanto E. Gunawan, Marthe Lir Vian Tus. (2019). Redesigning Warehouse Layout Based on Warehouse Management System Policy to Minimize Material Handling Cost. International Journal of Mechanical Engineering and Technology, 10(5), 61-76.

Hendy Tannady, Edy Gunawan, Filscha Nurprihatin, Fuji Rahayu Wilujeng. (2019). Process Improvement to Reduce Waste in the Biggest Instant Noodle Manufacturing Company in South East Asia. Journal of Applied Engineering Science, 17(2), 203-212.

Filscha Nurprihatin, Agnes Octa, Tasya Regina, Tony Wijaya, Julliete Luin, Hendy Tannady. (2019). The Extension Analysis of Natural Gas Network Location-Routing Design through the Feasibility Study. Journal of Applied Research on Industrial Engineering, 06(2), 108124.

Hendy Tannady, Yana Erlyana, Filscha Nurprihatin. (2019). Effects of Work Environment and Self Efficacy Toward Motivation of Workers in Creative Sector in Province of Jakarta, Indonesia. Quality : Access to Success, 20(172), 165-168. 
Filscha Nurprihatin, Meilily Angely, Hendy Tannady. (2019). Total Productive Maintenance

Policy to Increase Effectiveness and Maintenance Performance Using Overall Equipment Effectiveness. Journal of Applied Research on Industrial Engineering, 06(3), 184-199.

Fergyanto E. Gunawan, Johanes Fernandes Andry, Hendy Tannady, Rourentsia Meylovsky. (2019). Designing Enterprise Architecture Using TOGAF Framework in Meteorological, Climatological, and Geophysical Agency. Journal of Theoretical and Applied Information Technology, 97(20), 2376-2385.

Hendy Tannady, Fergyanto E. Gunawan, Andreas Heryjanto. (2020). Moderation Effect Of Work Motivation Toward Employee Engagement Of Worker In Textile Industry In Province Of Central Java, Indonesia. Test Engineering and Management, 83, 9716-9723.

Endang Pitaloka, Hendy Tannady. (2020). Analysis of Citizen Satisfaction on National Agency of Drug and Food Control of Republic Indonesia (NADFC). Technology Reports of Kansai University, 62(3), 1069-1075.

Johanes Fernandes Andry, Hendy Tannady, Fergyanto E. Gunawan. (2020). Purchase Order Information System Using Feature Driven Development Methodology. International Journal of Advanced Trends in Computer Science and Engineering, 9(2), 1107-1112.

Hendy Tannady, Johanes Fernandes Andry, Fergyanto E. Gunawan, Jordy Mayseleste. (2020). Enterprise Architecture Artifacts Enablers for IT Strategy and Business Alignment in Forwarding Services. International Journal of Advanced Trends in Computer Science and Engineering, 9(2), 1465-1472.

Fergyanto E. Gunawan, Yohanes Totok Suyoto, Hendy Tannady. (2020). Factors affecting job performance of hospital nurses in capital city of Indonesia: Mediating role of organizational citizenship behavior. Test Engineering and Management, 83, 22513-22524.

Hendy Tannady, Johanes Fernandes Andry, Bernadus Gunawan Sudarsono, Yuliawan Krishartanto. (2020). Enterprise Architecture Using Zachman Framework at Paint Manufacturing Company. Technology Reports of Kansai University, 62(4), 1869-1883. 